\title{
FORMAÇÃO DE PROFESSORES DE EDUCAÇÃO FÍSICA PARA A CIDADE E O CAMPO
}

\author{
Celi Zulke TafFarel* \\ SOLANGE LACKS** \\ Cláudio de Lira SANTOS Júnior ${ }^{* * *}$ \\ Marise CARVALho ${ }^{* * * *}$ \\ AdRIANA D'AgOSTINI ${ }^{* * * * *}$ \\ MAURO TITTON ${ }^{* * * * * *}$ \\ NAIR CASAGRANDE ${ }^{* * * * * *}$
}

\section{RESUMO}

O texto propõe a formação de professores de Educação Física baseada em cinco fontes de dados a saber: 1. Demandas apresentadas pela escola pública, pelos movimentos sociais e entidades relacionadas à aérea de esporte e lazer da cidade e do campo; 2. Avaliação das condições de oferecimento dos cursos de educação física; 3 . Balanço crítico da produção do conhecimento sobre o tema; 4 . Embate de projetos presentes na definição de diretrizes para a formação de professores de Educação Física, na criação do Sistema CREFE/CONFEF e na aprovação da regulamentação da profissão; 5. Proposições para reestruturação do currículo de formação de professores de Educação Física apresentado pelo Grupo LEPEL/FACED/UFBA.

PALAVRAS-CHAVE: formação de professores - currículo - trabalho pedagógico

* Doutora em Educação pela Unicamp, mestre em Ciências do Movimento Humano pela UFSM, professora da UFBA e pesquisadora do CNPq.

** Doutora em Educação pela UFBA, mestre em Ciências do Movimento Humano pela UFSM e professora da UFS.

*** Doutor em Educação pela UFBA, mestre em Educação pela UFPE e professor da UEFS.

**** Professora mestre em Educação pela UFBA e estagiária científica LEPEL/FACED/ UFBA.

***** Professora mestre em Educação Física pela UFSC e doutoranda em Educação pela FACED/UFBA.

******* Professor mestre em Educação pela UFBA e doutorando em Educação pela UFSC.

${ }^{* * * * * * *}$ Mestre em Serviço Social pela UFPE, professora da UFBA e doutoranda em Educação pela UFRGS. 


\section{INTRODUÇÃO}

formação dos professores de Educação Física no Brasil situa-se no
contexto da formação universitária, predominantemente, na formação de licenciandos. A formação é regida pelas seguintes leis: Diretrizes para formação de profissionais de educação física na graduação - Resolução $\mathrm{n}^{\circ} 7$, de 31 de março de 2004 e pelas Diretrizes para a formação de professores - Licenciatura - para a educação básica - Resolução CNE/01 de 18/02/2002 e Resolução CNE/CP n ${ }^{\circ}$ 2, de 19 de fevereiro de 2002. Um balanço preliminar sobre a situação da Educação Física no Brasil nos permite verificar a existência aproximada de 460 cursos habilitados, sendo 83 no nordeste e destes, 21 na Bahia. Estes cursos formam, na Bahia, aproximadamente 330 profissionais por ano; no nordeste são 2.430 e no Brasil, 13.980 profissionais. Desse total aproximado de formandos, muitos optam em continuar a carreira acadêmica e outros retornam mais tarde aos estudos em busca de formação continuada. Isto nos indica uma demanda para a pós-graduação reprimida no nordeste do Brasil por falta de opções para estudos em instituições públicas que integrem ensino-pesquisa-extensão, graduação-pós-graduação, universidade-sociedade.

São ao todo, 17 cursos de pós-graduação stricto sensu - mestrado e doutorado - existentes no Brasil. Predominam na graduação, as instituições privadas e na pós-graduação, as públicas. Como as demais licenciaturas e formações universitárias, segundo Taffarel (1993), a formação nos cursos de Educação Física apresenta os seguintes problemas:

a) problemas teóricos - o campo de conhecimento está em construção e sofre a disputa de influências ainda fortes de diferentes áreas do conhecimento - área médica e áreas das ciências humanas e sociais, sendo evidentes teorias positivistas, idealistas, orientando o trato com o conhecimento no currículo;

b) problemas epistemológicos - evidentes na produção do conhecimento com a hegemonia de uma abordagem nos estudos - a empíricoanalítica, com ascensão da abordagem hermenêutico-fenomenológica e, atualmente, com evidências de ênfase em teorias pós-modernas que se caracterizam pela perda de referências históricas e pelo "giro lingüístico" que coloca no centro a predominância das representações, da cultura e da linguagem como determinante da ontogênese do ser social, 
com mínimas evidências de emprego de teorias críticas e abordagens dialética, materialista e histórica na produção científica;

c) problemas de financiamento público - decorrente dos ajustes estruturais que desresponsabilizam o Estado de suas funções propícias e estabelecem relações promíscuas entre público-privado com o repasse de verbas públicas aos setores da economia privada, ocorrendo isto tanto no Ministério da Educação como no Ministério do Esporte;

d) problemas de oferecimento das condições objetivas para funcionamento dos cursos - infra-estrutura inexistente ou incompatível ou insuficiente com as exigências do curso; corpo docente sem titulação e baixa qualificação nas particulares e com o trabalho docente precarizado e nas públicas com arrocho salarial de década e com trabalho incentivado por gratificações produtivistas e com evidências de despolitização; corpo discente cada vez mais despreparado para as universidades em decorrência da péssima qualidade do ensino básico e pela falta de assistência estudantil para se manter nas universidades; com um corpo técnico-administrativo que vê dia-a-dia seus postos de serviço sumindo, pela via das fundações privadas que como parasitas sugam recursos e postos de serviços e pela via da desqualificação por falta de planos e projetos de qualificação e requalificação profissional;

e) problemas curriculares - com inconsistente base teórica; processos de gestão antidemocráticos; dicotomia teoria-prática; currículos extensivos e desportivizados; sem articulação entre ensino-pesquisaextensão; com teorias do conhecimento idealistas, voltados para atender demandas de mercado, com perfil de formação direcionado às competências mínimas;

f) problemas políticos - com a perda da autonomia universitária com a ingerência nos rumos que deve ter a formação pela forte influência, por um lado, do poder executivo e legislativo nas universidades e faculdades, através de medidas legais que vão desde a definição de diretrizes até as questões de orçamento para a educação superior, contratação de pessoal, programas e projetos que interessam ao governo e, por outro lado, a pressão exercida pelos organismos internacionais, como FME, Banco Mundial, Bird, pelas empresas, conselhos, como o Conselho Federal de Educação Física e sua ação corporativa e autoritária sobre o trabalho pedagógico, bem como, outros mecanismos que representam e defendem os interesses do capital e sua necessidade de subordinar a formação de professores ao projeto de mundialização do 
capital, a nova "governança mundial". A profissão de Educação Física está regulamentada e o Sistema Conselho Federal de Educação Física/ Conselhos Regionais de Educação Física (CONFEF/CREFE) - Lei ${ }^{\circ}$ 9.696/98 - em pleno funcionamento, apesar dos protestos de pesquisadores, professores e movimento estudantil e dos embates jurídicos existentes. A isto se soma a ausência de uma política articulada nacionalmente, por um pacto federativo, entre a federação, os estados e os municípios para o enfrentamento das questões referentes à educação, à educação física, ao esporte e lazer na cidade e no campo.

Estes problemas foram localizados a partir de investigações nas seguintes fontes de dados: 1 . Demandas apresentadas pela escola pública, pelos movimentos sociais e entidades relacionadas a área de esporte e lazer da cidade e do campo; 2. Avaliação das condições de oferecimento dos cursos de Educação Física; 3. Balanço crítico da produção do conhecimento sobre o tema; 4 . O embate de projetos presente na definição de diretrizes para a formação de professores de Educação Física e na criação do CONFEF/CREFE e na aprovação da regulamentação da profissão.

Responder a este conjunto de problemas não é tarefa simples e, muito menos, de um ou outro ou de poucos. É uma tarefa histórica a ser enfrentada por coletivos que reconhecem que a formação de professores é estratégica para a manutenção ou não, de um determinado modo de vida na sociedade; a manutenção ou não, do modo do capital organizar a vida. A formação de professores de Educação Física pode, portanto, estar articulada com o que reivindicam as amplas massas ou com o que necessita o capital e seus aliados para manter a sociedade de classes. Para enfrentar estes complexos problemas se faz necessário compreender o que se passou em nosso país e determinou o estado em que vivemos atualmente: um país cuja economia está entre as maiores do mundo, mas mesmo assim mantém em seu solo uma população cada dia mais pobre e miserável, exaurida e esgotada pela superexploração e pela carência dos serviços públicos, entre os quais a educação, o esporte e o lazer.

\section{DESENVOLVIMENTO}

Para aprofundar a discussão sobre formação de professores, apresentamos dados sobre a situação do Brasil e sua economia baseada no modelo agroindustrial e duas propostas de diretrizes. Uma delas é a que 
foi aprovada pelo Conselho Nacional de Educação (Resolução n. 7, de 31 de março de 2004), cuja revogação é reivindicada pelo Movimento Nacional dos Estudantes de Educação Física, e, a outra, é a proposta desenvolvida a partir de estudos expressos em dissertações de mestrado e teses de doutorado pelo Grupo LEPEL da Faculdade de Educação da Universidade Federal da Bahia (FACED/UFBA).

No Brasil, a lógica capitalista industrial-financeira penetrou no campo com mais ênfase na década de 1960, com a Revolução Verde. Esta consistiu na mudança das bases tecnológicas da produção agropecuária, que passou a sustentar-se na dependência dos agricultores familiares ao capital industrial (máquinas, equipamentos, fertilizantes e venenos). Nos fins dos anos 70, já se percebia o esgotamento desta concepção de produção pelo aumento de um proletariado rural e o abarrotamento dos grandes centros urbanos com o êxodo rural.

A modernização conservadora deu-se com a permanente concentração da propriedade da terra e teve as seguintes conseqüências: destruição das terras agricultáveis, com o uso inadequado de máquinas agrícolas, insumos e agrotóxicos, poluindo água, solo, ar, plantas e animais; crédito rural para custeio, investimento e comercialização, especialmente para as grandes propriedades; utilização irracional e predatória dos recursos naturais; expansão da lavoura de produtos designados à exportação e sobre a base da monocultura em grandes propriedades; produção para o mercado interno feito por médios e pequenos produtores cada vez mais integrada à agroindústria; produção de sementes melhoradas e desenvolvimento das genéticas animal e vegetal controladas por grandes empresas, em parte multinacionais; diminuição do número de propriedades com mão-de-obra familiar nas comunidades rurais e diminuição do número de famílias no meio rural, aumentando a pressão nos grandes centros urbanos despreparados para receber contingentes humanos advindos do êxodo rural; alta incidência de envenenamento, mortes, suicídios e casos de câncer no meio rural provocada pelo uso de agrotóxicos; desvalorização da cultura e dos saberes do campo.

Este "pacote tecnológico" intensificou a pobreza, o desemprego, as questões ambientais, a violência e a desigualdade. Tudo isto pode ser, hoje, precisamente identificado na situação dos grandes centros urbanos, que subordinou a agricultura brasileira à lógica do capital industrial, financeiro e comercial, e produziu um desenvolvimento desigual nos diferentes produtos e nas diferentes regiões. Além do mais, nega- 
se o conhecimento dos trabalhadores, fazendo com que eles percam o domínio das tecnologias da agricultura, gerando a perda da confiança dos agricultores em sua própria capacidade e no valor de seus conhecimentos.

Essa realidade brasileira e suas contradições apontam para projetos de sociedade que se confrontam. Um, alicerçado na exploração das forças produtivas e, outro, pautado na justiça social, na vida digna, organizada para além do capital. Subjaz a cada, um projeto histórico (de sociedade), conseqüentemente, projetos educacionais diferenciados. Assim, a formação dos professores em geral e, em especial, da Educação Física, é estratégica para o povo brasileiro da cidade e do campo, e sua defesa, sob base de uma teoria crítica do conhecimento e do currículo, é de fundamental importância neste enfrentamento.

A escola da cidade e do campo, como parte desta estrutura e como instituição formadora, deve ser espaço de debate e aprofundamento das problemáticas sociais e de busca de soluções. A educação da cidade e do campo traz essa concepção de escola: espaço de formação para um processo de transformação social. A educação e a educação física, o esporte e o lazer são formas de ação político-social que dão rumo à formação de um povo e, portanto, formar professores voltados exclusivamente para mercados de trabalho ligados à indústria da beleza, do culto ao corpo - a corpolatria - voltados ao esporte de espetáculo, ao esporte de alto rendimento e "lucros", compromete o desenvolvimento de um dado projeto histórico.

Os cursos de Educação Física no Brasil não formam para que os professores enfrentem a situação na cidade, muito menos no campo. Para exemplificar, vamos demonstrar o perfil do esporte segundo dados do Suplemento de Esporte da Pesquisa de Informações Básicas Municipais do IBGE (Munic). A pesquisa mostra que,

apesar de 93,6\% das cidades brasileiras realizarem eventos esportivos com execução ou participação da prefeitura, a estrutura financeira, institucional, de pessoal, equipamentos e instalações para tanto ainda é deficiente. O pessoal ocupado com esporte, em 2003, representava apenas $1,4 \%$ em relação ao total de pessoal das prefeituras; mais de $88 \%$ dos municípios não possuíam Conselho Municipal de Esporte; os recursos aplicados em desporto e lazer atingiram menos de $1 \%$ do total das despesas das prefeituras; menos da metade das cidades faziam parcerias ou 
convênios voltados para o esporte; e $88 \%$ das escolas municipais não possuíam instalações esportivas - quadro ainda mais grave nas áreas rurais. O suplemento confirma que o Brasil é mesmo o país do futebol: $94,5 \%$ das prefeituras realizavam eventos nessa modalidade; $27,7 \%$ das cidades tinham estádios de propriedade e/ou gestão da prefeitura (segundo equipamento esportivo mais freqüente), e os campos de futebol estavam presentes em 74,8\% dos municípios (IBGE, 2006, p. 1).

A pesquisa faz parte de um convênio entre o IBGE e o Ministério do Esporte e foi realizada em 2003, em 5.557 cidades. Quanto aos dados da educação no campo, constatamos uma complexa situação para a qual não estão sendo formados professores no Brasil. Ousamos afirmar que nenhuma licenciatura forma para enfrentar a situação no campo. O perfil da educação e da educação física, esporte e lazer no campo, apesar de intensa urbanização, é de 32 milhões vivendo em franca desvantagem nas políticas sociais. Em relação à escolaridade, os índices de analfabetismo são preocupantes: $29,8 \%$ da população adulta (de 15 anos ou mais). Das crianças entre 10 e 14 anos, 95\% encontram-se na escola, mas $72 \%$ apresentam defasagem escolar em relação às crianças urbanas, de 50\%. Entre os jovens de 15 e 17 anos, somente $66 \%$ freqüentam a escola, e 17\% ainda estão matriculados nas séries iniciais do ensino fundamental. ${ }^{1}$

A rede de ensino de educação básica da área rural corresponde a 50\% das escolas do país. Aproximadamente a metade dessas escolas tem apenas uma sala de aula e oferece exclusivamente o ensino fundamental I, representando $15 \%$ da matrícula nacional. Os estabelecimentos são, em sua maioria, formados por turmas multisseriadas ou unidocentes. Desses, 93\% pertencem à rede municipal. Quanto aos recursos disponíveis, $21 \%$ não possuem energia elétrica, e apenas 5,2\% dispõem de biblioteca e menos de $1 \%$ oferece laboratórios de ciências, de informática e acesso à internet.

Os professores da área rural, segundo Carvalho (2004), além da baixa qualificação e de salários inferiores, enfrentam questões de sobrecarga de trabalho, alta rotatividade e dificuldades de acesso e locomoção. Em relação à escolaridade, dos docentes do fundamental I apenas 9\% apresentam nível superior. Nos anos finais do fundamental II, o percentual de docentes apenas com ensino médio corresponde a 57\% do total. E dos 9.917 docentes do ensino médio, 22\% têm escolaridade 
do mesmo nível. Além disso, o campo sofre com a baixa oferta para os anos finais do fundamental e médio, porém com alto índice de transporte escolar para área urbana. Isso indica que a exclusão escolar se configura de diferentes formas ao longo do tempo pela negação do acesso à escolaridade, ao direito à educação para aqueles que vivem e trabalham no campo. Bem como, a negação da educação do campo, seus princípios político-pedagógicos estabelecidos nas Diretrizes, tendo como princípio maior a auto-organização dos estudantes para a participação em um processo social que exige uma revolução.

Por fim, em que bases formar professores para uma realidade complexa e contraditória que exige a formação humana na perspectiva da omnilateralidade, da emancipação humana e da transformação social - ou seja, na perspectiva da construção do projeto histórico socialista?

Para responder a tal desafio, apresentamos uma proposição de diretrizes para a formação de professores de Educação Física, quiçá, a ser adotada pela UFBA, mantida a prevalência da prerrogativa da autonomia universitária, científica e pedagógica, tão cara a uma universidade que se quer pública, laica e de qualidade socialmente referenciada.

\section{CARACTERIZAÇÃO DO CURSO}

Apresentamos, a seguir, os principais itens que caracterizam a perspectiva de curso de formação de professores de Educação Física que defendemos, encaminhando uma proposição de resolução interna às Instituições de Ensino Superior (IES) sobre o curso a ser oferecido, observando a autonomia universitária e a superação dos limites da atual Resolução 07/04, em vigor.

\section{DADOS DE IDENTIFICAÇÃO}

Reconhecemos ser imperiosa a compreensão do caráter multidisciplinar que caracteriza a formação e a atividade profissional/acadêmica na Educação Física, como também a necessidade da presença nos currículos de conhecimentos originários tanto do campo das Ciências Biológicas/Saúde como do das Ciências Humanas/Sociais, da Terra, das Ciências Exatas, da Filosofia e das Artes. Na perspectiva de superar a concepção fragmentada de ciência, propomos como matriz científica para a formação dos professores, a História: a história do homem e sua 
relação com a natureza, dos homens entre si e consigo mesmo. Tal proposta assegura-se quando da colocação da primeira pergunta ontológica para compreensão do ser humano - como o homem torna-se homem e como se dá o conhecimento?

A relação estabelecida pelo ser humano com a natureza e demais seres, para garantir sua existência, ocorre no curso da história, portanto, somente a partir da história enquanto ciência é possível tanto apreender e compreender o passado, o presente, quanto o futuro do ser humano. Ao longo da história, também se configura a cultura corporal e o trabalho pedagógico, pontos centrais que dão identidade à atividade do professor de Educação Física.

A Educação Física se caracteriza historicamente pelo trabalho pedagógico, da docência no campo da cultura corporal, ou seja, a atividade pedagógica no trato com o conhecimento da cultura corporal. Em qualquer campo de trabalho seja de produção de bens materiais ou imateriais - educação, lazer, saúde, competição de alto rendimento, produção de tecnologias esportivas e outros. Isto nos aponta a necessidade de considerarmos o princípio de estruturação da atividade pedagógica e o trato com o conhecimento da cultura corporal é a base da formação acadêmica e do trabalho do professor de Educação Física.

Conhecimento científico no currículo de formação de professores. A docência, entendida como trabalho pedagógico, é, portanto, a identidade profissional do professor de Educação Física. Isto pode ser verificado pelos fatos quando nos reportamos à atividade profissional e identificamos seu sentido, significados, finalidades, meios e métodos ao longo da história. Caracteriza-se, também, por tratar de um campo de conhecimento que se estrutura a partir das práticas históricas, socialmente produzidas, cientificamente estudadas e investigadas e, criativamente, ensinadas de geração a geração, referentes à cultura corporal. A consolidação desta identidade do professor de Educação Física para o exercício profissional requer, durante a sua formação acadêmica:

a) sólida formação teórica de base multidisciplinar e interdisciplinar na perspectiva da formação omnilateral;

b) unidade entre teoria/prática, que significa assumir uma postura em relação à produção do conhecimento científico que impregna a organização curricular dos cursos, tomando o trabalho como princípio educativo e como práxis social; 
c) gestão democrática - que permita a vivência e o trabalho com relações de poder democráticas, e não autoritárias;

d) compromisso social com ênfase na concepção sócio-histórica do trabalho, estimulando análises políticas sobre as lutas históricas pela superação da sociedade de classes, para que seja garantido o acesso aos bens a todos que dele participam em sua produção, especificamente no campo da cultura corporal;

e) trabalho coletivo, solidário e interdisciplinar, e trabalho pedagógico como eixo articulador do conhecimento para a formação omnilateral;

f) formação continuada para permitir a relação entre a formação inicial e continuada no mundo do trabalho;

g) avaliação permanente como parte integrante das atividades curriculares, de responsabilidade coletiva a ser conduzida à luz do projeto político-pedagógico da instituição, abarcando as dimensões da avaliação da aprendizagem, do docente, dos programas e projetos, da instituição.

\section{PRINCÍPIOS NORTEADORES DA PROPOSTA}

As Diretrizes Curriculares para os Cursos de Licenciatura Ampliada em Educação Física foram desenvolvidas em consonância com os princípios enunciados no Parecer n. 776/97, da Câmara de Educação Superior do Conselho Nacional de Educação (CES/CNE), constituindose num conjunto articulado de princípios e de orientações que devem ser considerados na proposição e no desenvolvimento curricular desta modalidade de curso.

Nelas, o currículo é concebido como fenômeno histórico, resultado das relações sociais, políticas e pedagógicas que se expressam na organização de saberes vinculados à formação do ser humano. $\mathrm{O}$ currículo pressupõe a organização interativa de conhecimentos pautados nas tradições cultural e científica do nível e/ou da área de formação, estabelecidos a partir das questões que emergem do contexto sócio-cultural, superando as visões de currículo que se caracterizam pela organização formal, linear e fragmentada de disciplinas convencionais, e por excessiva carga de disciplinas obrigatórias com grandes vínculos de pré-requisitos.

A intenção é consolidar uma base teórica, segundo proposta de Santos Junior (2005) fazendo-a a partir da Teoria do Conhecimento que possibilita a construção do conhecimento, segundo Lacks 
(2004) como categorias da prática, permitindo a organização do conhecimento em ciclos - da constatação de dados da realidade, às sistematizações, generalizações, ampliações e aprofundamentos -, configurando os sistemas de complexos temáticos que por sua vez estruturam programas como os de vida para a formação humana. Para consolidar uma base teórica, a prática, enquanto práxis social, deve ser o eixo articulador do conhecimento no currículo. Concebemos currículo, portanto, como referência de organização do trabalho pedagógico que fornece direção política e pedagógica à formação comum, unificadora nacionalmente.

Essa visão está relacionada ao padrão unitário de qualidade para oferecimento de cursos e, se desdobra, considerando as especificidades e particularidades do Brasil. As Diretrizes aqui apresentadas foram formuladas a partir do reconhecimento de que a autonomia e a flexibilidade preconizadas pela Lei de Diretrizes e Bases da Educação Nacional (Lei n. 9394/96) são inequívocas e representam ponto de apoio para a ação pedagógica. A autonomia institucional diz respeito ao preceito legal, estabelecido na Constituição Federal em seu Artigo 207. Para garantir a unidade nacional em torno de uma consistente formação acadêmica à área de Educação Física, assumimos a idéia da base comum nacional - que permitirá uma consistente formação teórica, interdisciplinar, a unidade teoria/prática, a gestão democrática, o compromisso social, o trabalho coletivo, a formação continuada, a avaliação permanente, na formação acadêmica, para que o graduado compreenda criticamente os determinantes e as contradições do contexto em que está inserido e seja capaz de reconhecer possibilidades, atuando na criação de condições objetivas para a transformação social.

A base comum nacional deverá, portanto, permitir o domínio do conhecimento e seus meios de produção, em uma perspectiva de totalidade, radicalidade e de conjunto, do conhecimento produzido e que permita relações e ações transformadoras na realidade, tendo no horizonte um projeto histórico de superação do modo do capital organizar a vida na sociedade - modo este criado nas relações humanas, com caráter duplo, contraditoriamente, de desenvolvimento das forças produtivas e de sua concomitante destruição. Em sendo resultante de ação humana é, portanto, factível de ser alterado. A partir dessas considerações gerais, as Diretrizes Curriculares para os Cursos de Licenciatura Ampliada em Educação Física foram desenvolvidas de modo a: 
- assegurar a autonomia das Instituições de Ensino Superior na composição da carga horária e duração dos cursos, bem como na especificação das unidades de estudo, observando-se o indicado na resolução que decorre deste parecer;

- assegurar a sólida formação básica na área e o aprofundamento de estudos em campos temáticos de ação profissional ou de formação acadêmica, principalmente os que são motivo de estudos e investigações pelos grupos de pesquisa da instituição;

- assegurar um processo de formação crítica que considere a articulação entre os conhecimentos de fundamentação e da atividade profissional com as dimensões política, humana e sociocultural;

- indicar os campos de conhecimento que comporão o currículo;

- estimular e aproveitar práticas independentes, visando estudo de formação complementar para fins de integralização do curso;

- encorajar o reconhecimento de conhecimentos adquiridos fora do ambiente universitário, inclusive experiências profissionais relevantes para a área de formação;

- fortalecer as unidades teoria-prática, tendo a prática como eixo articulador do currículo, a pesquisa como princípio educativo, por meio de atividades planejadas e sistematizadas em pesquisas, estágios, monitorias e atividades curriculares em comunidades e de extensão que deverão constituir-se como atividades essenciais do currículo da graduação;

- nortear a formação acadêmica tendo como referência os critérios da atualidade, da adequabilidade às capacidades dos estudantes, a discussão acumulada pela área, bem como as referências cientificamente atualizadas em áreas afins, que se mostram relevantes para a formação e para responder aos desafios educacionais da contemporaneidade;

- compreender uma concepção de formação humana omnilateral, em contra-ponto a concepção de competências, não incorrendo o reducionismo que induz a formação a um sentido meramente instrumental, mas sim, como uma política global que compreende dimensões humanas como a científica, pedagógica, técnica, ético-moral e política.

- assegurar tanto o domínio dos meios de produção do conhecimento - as categorias e leis do pensamento científico -, quanto os instrumentos referentes a métodos e técnicas de pesquisa, bem como, o acumulado historicamente acerca da cultura corporal - objeto de estudo dos cursos de formação do professor de Educação Física. 


\section{DADOS DA PROPOSTA}

\subsection{Denominação do curso}

Licenciatura Ampliada em Educação Física. Entendendo-se aqui como licenciado o que está apto a agir, atuar, desenvolver a atividade docente em diferentes campos de trabalho, mediado pelo objeto - cultura corporal.

\subsection{Perfil do graduado}

Licenciado Pleno em Educação Física com formação pautada em princípios éticos, políticos, pedagógicos e com base no rigor científico, de natureza generalista, humanista, crítica e reflexiva. Profissional qualificado para o exercício de atividades profissionais no campo da cultura corporal, que tenha como objeto as atividades corporais e esportivas, entendidas como um campo de estudo e ação profissional multidisciplinar, cuja finalidade é possibilitar a todos o acesso aos meios e ao acumulado historicamente, e que possibilite a construção deste acervo compreendido como direito inalienável de todos os povos, parte importante do patrimônio histórico da humanidade e do processo de construção da individualidade humana.

\subsection{O trabalho - o mundo do trabalho, os campos de trabalho e o mercado de trabalho}

Para fundamentar as diretrizes curriculares, estamos nos valendo da realidade do trabalho, estabelecendo referências claras sobre o que entendemos a respeito do trabalho humano, dos campos de trabalho e do mercado de trabalho.

O conceito de trabalho humano com o qual lidamos nos diz que "o primeiro pressuposto de toda a história humana é naturalmente a existência de indivíduos humanos vivos" (MARX; ENGELs, 1999, p. 27). E para se manter vivo, teve o homem que produzir seus meios de vida, meios estes modificados no curso da história, pelas ações dos próprios homens, em contato com a natureza, com os outros homens e consigo mesmo. Esta produção dos meios de vida, que tanto gera bens materiais quanto espirituais, se deu com base no trabalho humano. O trabalho é 
uma condição da existência humana, independentemente de qual seja a forma de sociedade.

Ainda segundo Marx e Engels (1999), o trabalho é uma necessidade mediadora do metabolismo entre o homem e a natureza e, portanto, da própria vida humana. O processo de trabalho é uma condição da existência humana; é comum a todas as formas de sociedade, mas se diferencia pelas relações sociais estabelecidas. O trabalho útil ou trabalho concreto é uma atividade produtiva de um determinado tipo, que visa a um objetivo determinado; seu produto é um valor de uso. $\mathrm{O}$ trabalho abstrato, ou trabalho socialmente necessário, por sua vez, é o dispêndio de força de trabalho humano que cria valor, mas com aspecto diferente. Esse trabalho está relacionado com a medida quantitativa do valor, pois determina a magnitute do valor, e igualmente encontra-se relacionado com o tempo de trabalho socialmente necessário à produção de um produto.

O trabalho útil, concreto, e o trabalho abstrato ou socialmente necessário, são, portanto, uma mesma atividade considerada em seus aspectos diferentes. Ao desenvolver esta conceituação, Marx (1983) leva em conta que o trabalho abstrato é uma abstração social, um processo social real bem específico do capitalismo. O processo de trabalho é aquele em que o trabalho é materializado em valor de uso, resultante da interação entre as pessoas e a natureza, ocorrendo aí modificações com base em propósitos humanos. Todo o produto do trabalho que entra no processo de troca converte-se em mercadoria. O trabalho convertese em valor de troca, tornando-se única "mercadoria" de uma parcela dos homens vendida por salários.

Estas relações de troca estabelecem referências de campos de trabalho - no caso da educação física, os campos da educação, lazer, saúde, treino, entre outros - e os mercados de trabalho, considerados locais específicos onde ocorre a troca de mercadorias, ou seja, o trabalhador vende sua força de trabalho em troca de salário. Entre os produtos que o trabalho do homem é capaz de gerar, existem aqueles que são produtos materiais, que se integram à lógica do valor de troca e se transformam em mercadoria nas relações sociais capitalistas. Mas existem também os produtos não-materiais que não se conformam facilmente à lógica capitalista de valor de troca. Encontramos aí os produtos que são consumidos no ato da produção, como o é a aula de um professor. 
É nesse quadro referencial teórico que pretendemos compreender o trabalho no campo da Educação Física, mais especificamente, sua objetivação na formação de profissionais do ensino nos cursos de Licenciatura Ampliada e responder à problemática já apontada por Freitas (1987 e 1995) sobre a materialização das relações de trabalho capitalista no processo de trabalho pedagógico e no trato com o conhecimento no Curso de Licenciatura Ampliada em Educação Física.

Privilegiamos esta abordagem por reconhecermos que a Educação Física, dentro do modo de produção capitalista, desenvolve-se a partir do confronto e do conflito entre os interesses de classes sociais antagônicas, na luta pela hegemonia de seus projetos históricos. Confrontam-se, portanto, forças sociais e políticas relacionadas com a estrutura social, com a divisão da sociedade em classes sociais. Consideramos imprescindível a explicitação não só dessas posições - visto que estamos tratando do rumo que deve ter, dentro de determinado projeto histórico, a formação dos professores de Educação Física -, como do papel que vêm exercendo a organização do trabalho pedagógico, a produção e a apropriação do conhecimento, dentro de uma dada conjuntura, de reconstituição mundial do capital frente ao agravamento da crise do capitalismo.

É nesta perspectiva que entendemos que devam ser colocadas as contribuições advindas de segmentos sociais organizados em torno da formação do professor de Educação Física, para levantar dados desta realidade, compreendê-los, interpretá-los, explicá-los e atuar sobre eles, à luz dos interesses de classe. A Educação Física é um campo profissional tradicional e contraditório existente no Brasil. Sofre, como todos os campos de atuação profissional, os mesmos determinantes próprios de uma sociedade organizada em classes, onde a maioria da população não tem acesso a bens culturalmente produzidos.

A relevância, importância, legalidade e legitimidade da Educação Física também apresenta profundas contradições visto ser ela um bem cultural, produzido socialmente, apropriado historicamente. Logo, como vivemos em uma sociedade de classes, a apropriação, o conhecimento e o reconhecimento deste bem estão na dependência da situação de classe e da consciência histórica da classe, ou seja, de sua capacidade de organização, reivindicação e conquistas.

No que diz respeito aos professores, eles estão sujeitos, como os trabalhadores em geral, a um processo de destruição, visto vivermos 
um período de forte tendência à destruição das forças produtivas, pela decomposição acelerada do modo de produção capitalista.

Por entendermos a necessidade de mudanças profundas e urgentes na formação do professor de Educação Física - para que o mundo do trabalho, os campos de trabalho e o mercado de trabalho sejam entendidos, compreendidos e reestruturados na perspectiva dos interesses dos trabalhadores e não na lógica do capital -, é que estamos propondo a identificar uma política global de formação do professor de Educação Física que permita uma consistente base teórica para a atividade pedagógica no campo da cultura corporal.

\subsection{A política global de formação (Competências e habilidades)}

A política global de formação que dará identidade profissional e que é necessariamente caracterizada historicamente pelo trabalho profissional tem o ato pedagógico e o trato com o conhecimento acerca da cultura corporal como identidade, abrangendo as dimensões humana e político-social, e tem por finalidade a formação omnilateral que significa, em última instância a superação da formação unilateral, altamente especializada e limitada.

A configuração das dimensões científicas, técnicas, pedagógicas, éticas, morais e políticas deve ser a concepção nuclear na orientação do currículo de formação inicial do professor de Educação Física. Além de dominar os processos lógicos de construção e os meios, técnicas e métodos de produção do conhecimento científico que fundamentam e orientam sua ação profissional, é imperioso que saiba mobilizar esses conhecimentos, transformando-os em ação moral, ética e política libertadoras, emancipatórias, na perspectiva da superação da sociedade de classes e, portanto, na perspectiva de uma filosofia da práxis social.

O professor de Educação Física, além do domínio dos conhecimentos específicos para sua ação profissional deve, necessariamente, compreender e enfrentar as questões envolvidas com o trabalho capitalista, seu caráter e organização. Isto implica em compreender e agir sobre o duplo caráter que assume o trabalho: um caráter ontológico de formação do ser humano e outro, de trabalho alienado no modo de produção capitalista. Nesta perspectiva, deve-se criticar a base técnica e tecnológica do trabalho do professor de Educação Física e buscar a construção de novas bases científicas para organização do trabalho, a 
saber, um trabalho na linha do trabalhar emancipatório, solidário, em grupo, com autonomia e auto-organização, para tomar decisões, bem como se responsabilizar pelas opções feitas.

É preciso também que o professor saiba avaliar criticamente sua própria atuação e o contexto em que atua, e que saiba interagir cooperativamente tanto com sua comunidade profissional, quanto com a sociedade em geral. O desenvolvimento de tais dimensões requeridas na formação do professor de Educação Física deverá ocorrer a partir de experiências de interação teoria e prática, em que toda a sistematização teórica deve ser articulada com as situações de ação profissional balizadas por posicionamentos reflexivos com consistência e coerência conceitual.

Tais dimensões da formação humana não podem ser adquiridas apenas no plano teórico, dos fundamentos, nem no estritamente instrumental. É imprescindível, portanto, que haja coerência entre a formação oferecida, as exigências práticas esperadas do futuro profissional e a necessidade de emancipação e democratização política, humana e sociocultural.

Portanto, tais dimensões da formação humana não podem ser compreendidas e nem reduzidas às dimensões do aprender a aprender, do aprender a fazer, do aprender a ser e aprender a conviver. Implicam também a consciência de classe, a formação política e a organização revolucionária.

O pressuposto dessas diretrizes identifica-se, portanto, com uma concepção de currículo compreendido como processo de formação da competência humana histórica para a emancipação. Sendo assim, a formação é, sobretudo, a condição de refazer permanentemente as relações com a sociedade e a natureza, objetivando a superação da alienação humana.

Nesta perspectiva, a formação em Educação Física deve privilegiar:

- a cultura científica de base em ciências humanas, da terra, exatas, sociais e biológicas de modo a contribuir para formação humana emancipatória e omnilateral, para a adequação e o enriquecimento da ação profissional ética, bem como para possibilitar que a cultura corporal, tematizada nas manifestações clássicas e emergentes da Educação Física, seja compreendida e analisada a partir da articulação das suas dimensões científica, técnica, moral e ética, política, pedagógica; 
- a capacidade para analisar reflexivamente e para agir eticamente nas situações da atividade profissional, a partir de uma atitude crítica identificada com os ideais e valores de uma sociedade democrática que supere as relações do modo de produção capitalista;

- o domínio tanto dos meios de produção como de conhecimentos clássicos e essenciais relacionados à cultura geral e à formação específica que são objetos das atividades humanas e profissionais, adequandoos às necessidades de emancipação sociocultural dos seres humanos e ao desenvolvimento democrático da sociedade;

- a atitude crítico-reflexiva sobre os resultados de pesquisa para a adequação e o aprimoramento das ações humana e profissional em prol da consecução dos objetivos específicos e de formação sociocultural planejados para o público alvo e a sociedade em geral;

- a compreensão e o domínio do processo de ação profissional nos campos de trabalho relacionados à tradição e com base no emergente da área e nas suas relações com o contexto no qual estão inseridos;

- a resolução de problemas concretos da prática profissional e da dinâmica das instituições afins, zelando pela aprendizagem e pelo desenvolvimento das pessoas;

- a consideração crítica das características, interesses e necessidades das pessoas nos momentos de planejamento, aplicação e avaliação dos programas de intervenção profissional;

- a sistematização e socialização da reflexão sobre a prática profissional;

- a compreensão e as implicações sociocultural, política, econômica e ambiental do campo da cultura corporal e esportiva de modo a agir de forma crítica-reflexiva;

- a demonstração da capacidade de lidar crítica e autonomamente com a literatura pertinente e atualizada e com os diversos tipos de produção dos conhecimentos afins, reconhecendo a transitoriedade dos mesmos;

- o uso de recursos da tecnologia da informação e da comunicação de forma a ampliar e diversificar as formas de interagir e compartilhar com as fontes de produção e difusão de conhecimentos e de tecnologias, bem como para qualificar a intervenção profissional;

- a demonstração de sentido de cooperação, autodeterminação, auto-organização, solidariedade na relação com as pessoas, clareza, 
adequação e objetividade nas formas de comunicação escrita, verbal e não-verbal e desenvoltura no fazer didático, de modo a conduzir e compartilhar adequadamente sua atividade profissional;

- a capacidade de argumentação de modo a saber justificar e articular sua visão de mundo e sua prática profissional com a construção do projeto histórico para além do capital, bem como balizar sua ação profissional à luz da crítica às teorias produzidas a partir dos campos de conhecimento específicos e afins.

As dimensões gerais da formação deverão ser contextualizadas e complementadas considerando as relações entre o geral da formação humana, o específico próprio à ação do professor, em particular do professor de Educação Física, definidas pela Instituição de Ensino Superior.

\section{CONTEÚDOS CURRICULARES}

O conhecimento é fruto da práxis humana e a origem dos conteúdos decorre da atividade prática do homem para atender interesses específicos de classes sociais específicas. Os fenômenos da realidade são parte de um processo inerente ao desenvolvimento histórico geral e por isso a cientificidade e historicidade do processo cognitivo. O pensamento teórico-científico explica que a base e o critério para separar as classes de objetos são os diferentes tipos de atividades encaminhadas a satisfazer necessidades sociais. Assim faz-se evidente que o objeto de estudo da Educação Física é o fenômeno das práticas cuja conexão geral ou primigênia - essência do objeto e o nexo interno das suas propriedades - determinante do seu conteúdo e estrutura de totalidade, é dada pela materialização em forma de atividades - sejam criativas ou imitativas - das relações múltiplas de experiências ideológicas, políticas, filosóficas e outras, subordinadas às leis histórico-sociais.

O geral dessas atividades é que são valorizadas em si mesmas; seu produto não material é inseparável do ato da produção e recebe do homem um valor de uso particular por atender aos seus sentidos lúdicos, estéticos, artísticos, agonísticos, competitivos e outros relacionados à sua realidade e às suas motivações. Elas se realizam com modelos socialmente elaborados portadores de significados ideais do mundo objetal, das suas propriedades, nexos e relações descobertas pela prática social conjunta. 
No momento damos, a essa área de conhecimento, que se constrói a partir dessas atividades, segundo proposta do Coletivo de Autores (1992) a denominação de "Cultura Corporal". Os currículos plenos para os Cursos de Licenciatura Ampliada em Educação Física terão, portanto, como objeto a cultura corporal, como eixo articulador do conhecimento a prática social (práxis) e como matriz científica a história.

Os conhecimentos serão tratados por sistemas de complexos temáticos conforme proposição de Taffarel e Colavolpe (2006) e relacionados a: Conhecimentos de Formação Ampliada, Conhecimento Identificador da Área e Conhecimento Identificador do Aprofundamento de Estudos. Os Conhecimentos de Formação Ampliada são aqueles que permitem uma compreensão de conjunto, radical e de totalidade comum a qualquer tipo de formação profissional. Compreendem os estudos acerca das relações do ser humano com a natureza, com os demais seres humanos na sociedade, com o trabalho e com a educação. O Curso de Licenciatura Ampliada em Educação Física, nesta parte, será guiado pelo critério da orientação científica, da integração teoria-prática e pelo critério do conhecimento das relações do ser humano, do mundo do trabalho, da cultura corporal e da sociedade. Isto possibilitará uma formação abrangente para a competência profissional de um trabalho em contextos histórico-sociais específicos, promovendo um contínuo diálogo entre as áreas de conhecimento científico e a especificidade da Educação Física. Guiar-se-á, também, pelo estudo das distintas manifestações clássicas e emergentes da cultura corporal e esportiva, identificadas com a tradição da Educação Física.

O Conhecimento Identificador da Área compreende o estudo, segundo Taffarel e Teixeira (2006) das relações entre cultura corporal e natureza humana, cultura corporal e territorialidade, cultura corporal e mundo do trabalho, cultura corporal e política cultural. Os Conhecimentos Identificadores do Aprofundamento do Estudo serão delimitados por cada Instituição de Ensino Superior (IES), partindo de sua capacidade de investigação, de sua instalação de grupos de pesquisa, de seus programas de pós-graduação integrados com a graduação. Desta estrutura de organização e sistematização do conhecimento, a IES poderá propor um ou mais campos de aprofundamento de estudos, de acordo com suas investigações, grupos e linhas de estudos e pesquisas a ser organizado a partir dos complexos temáticos. 
Quanto ao tempo de integralização dos Cursos de Licenciatura Ampliada em Educação Física será definido pelas Instituições de Ensino Superior, respeitando o mínimo de duração e de carga horária de quatro (4) anos e de $2.800 \mathrm{~h}$, respectivamente, das quais 800 horas serão destinadas à prática do ensino e estágio supervisionado, 1.800 para os conteúdos científico-culturais e 200 horas para outras formas de atividades acadêmico-científicas.

A Prática do Ensino e o Estágio Profissional Curricular Supervisionado são obrigatórios, devendo ser desenvolvidos em campos de ação profissional e com cumprimento de carga horária mínima de acordo com legislação específica do CNE, a saber, de 400 horas para a Prática do Ensino e 400 para o Estágio Profissional Curricular Supervisionado. O Estágio e a Prática de Ensino deverão ser implementados ao longo do curso em ciclos de ensino, estruturados para viabilizarem a articulação da produção do conhecimento científico a partir da prática. A Prática do Ensino compreenderá os ciclos de constatação de dados da realidade, sistematizações, generalizações, confrontos de teorias, ampliação e aprofundamento com vivências e experiências práticas em projetos de pesquisa sob a coordenação e orientação de professores pesquisadores da instituição. O Estágio Profissional Curricular Supervisionado somente iniciará na metade do curso, metade da carga horária total cumprida e contará, além da orientação de professor do Curso, com supervisão, que deve ser de profissionais formados, devidamente contratados nos locais de trabalho.

Para os cursos de Licenciatura Ampliada de Educação Física será exigida a orientação científica desde o primeiro ciclo de formação, com inserção em grupos e linhas de pesquisa, que culminará, também, na elaboração de um trabalho de conclusão de curso, sob forma de monografia de base, a partir de orientação acadêmica de professores pesquisadores.

As atividades complementares deverão ser implementadas, acompanhadas e avaliadas durante todo o curso. As Instituições de Ensino Superior criarão mecanismos para aproveitamento dos conhecimentos adquiridos pelo estudante por meio de estudos e práticas independentes de presenciais e/ou a distância.

A avaliação do Curso, dos docentes e discentes será permanente, integrada às atividades curriculares, tendo como referência o padrão nacional unitário de qualidade e a base comum nacional para a formação 
de professores, para a consolidação de uma consistente base teórica interdisciplinar na formação acadêmica da graduação.

\section{CONSIDERAÇÕES GERAIS}

O Curso de Licenciatura Ampliada em Educação Física deverá ter um projeto pedagógico construído coletivamente por meio da articulação entre ensino, pesquisa e extensão, referenciado em um projeto histórico claro e explícito, que supere as relações do modelo do capital organizar a vida na sociedade e, que tenha, segundo Taffarel e Dantas Filho (2006), como matriz científica a história e como eixo articulador do conhecimento a prática enquanto práxis social. O currículo do Curso de Licenciatura Ampliada em Educação Física deverá, necessariamente, ser estruturado tendo as atividades de pesquisa e de extensão como mediadoras da formação. A pesquisa como possibilidade de acesso ao conjunto de conhecimentos produzidos, aos seus modos de produção e como instância de reflexão crítica sobre a realidade; e a extensão considerada como possibilidade de interlocução e ação na realidade social, a partir da pesquisa.

\section{CONCLUINDO}

Vivemos em meio aos pobres, cuja única riqueza é sua força de trabalho e sua ânsia de viver. É uma pobreza ativa, como dizem Picanço e Tiriba (2004), onde os sujeitos desenvolvem capacidades, energias e forças reais para satisfazer suas necessidades básicas; para isto os pobres se organizam, enfrentam seus problemas, são capazes de gerir a produção sem nenhum ou quase nenhum acesso à educação ao esporte e ao lazer.

Provavelmente, estamos esboçando, aqui no Brasil, a partir de nossas experiências concretas, frente aos desafios impostos, segundo George (1995), pelas políticas de perfil liberal, com grandes e agudas problemáticas sociais, categorias de pensamento que contribuirão, a partir da prática, para o desenvolvimento teórico da área - uma delas é a metodologia aberta e construída a partir das experiências com os movimentos de luta que reivindicam direitos e defendem educação, esporte e lazer para todos. 
Este esforço pode ser reconhecido não só nas pesquisas já em desenvolvimento, mas, também na busca do intercâmbio acadêmico e do diálogo científico com pesquisadores de diferentes áreas do conhecimento e de diferentes regiões.

A formação de professores é um problema de todas as licenciaturas. Concluímos por fim, quer seja na cidade ou no campo, teremos que responder aos desafios educacionais. $\mathrm{O}$ avanço do imperialismo senil, a acentuação das desigualdades e a geração destas diferenças pelas desigualdades econômicas, políticas e sociais indicam somente a tendência à destruição própria do sistema capitalista. Nos cabe investigar que proposições afloram no âmbito das escolas, dos movimentos sociais, das organizações populares, segundo Gadotti e Gutierrez (1993) relacionadas com a educação, esporte e lazer, especificamente no Nordeste do Brasil, onde as pessoas, na maioria, lutam para manter suas vidas em relações sociais baseada na economia da sobrevivência, da subsistência, na economia popular solidária, orgânica e articulada com a economia de mercado do grande capital industrial, a economia especulativa, a economia estatal lucrativa e suas "estratégias de desenvolvimento subalterno e suicida".

A escola, por seu lado, continua segregadora e elitista. A história e as experiências passadas já demonstraram o que significam as ingerências de organismos internacionais nas políticas públicas para manutenção e acentuação deste quadro. Programas do tipo "Aliança Para o Progresso" e acordo como os "Acordos MEC-USAID”, engendrados durante os regimes militares já deixaram claro a que vieram, pois desmantelaram qualquer iniciativa revolucionária na educação, e o exemplo clássico, segundo Gadotti (1996), é Paulo Freire. No momento em que seu trabalho foi reconhecido como capaz de educar politicamente, o consideraram subversivo. Realmente, os conflitos entre os fazendeiros e trabalhadores tornaram-se mais intensos. O programa de alfabetização defendido por Paulo Freire mostrou-se capaz de desenvolver a consciência crítica, criando senso de responsabilidade e capacidade moral para mudar a vida e o mundo ao seu redor.

Quando se identificou que a pedagogia do oprimido, proposta por Freire (1977) poderia ampliar o grau de consciência de classe, financiamentos foram cortados, Paulo Freire banido do país, exilado, apagado da memória de gerações. Balanços sobre acordos de coope- 
ração internacional deixam evidentes, por exemplo, ser a América Latina considerada "território dos norte-americanos". As investidas da Comunidade Comum Européia, no campo dos intercâmbios, esbarram com a determinação dos organismos internacionais (BID, BM e FMI) de interferirem na definição de políticas educacionais brasileiras. Os documentos em geral elaborados pelos organismos internacionais, na década de 1990, circunscrevem-se ao binômio "pobreza e segurança", tendo como eixo articulador a imprescindível necessidade, segundo Chesnais (1996) de adequar os países periféricos à lógica da mundialização financeira.

Nesta lógica, a educação e o esporte são os principais instrumentos de "alívio à pobreza" e de garantia de desenvolvimento dos países periféricos. Dentro deste contexto, a formação de professores com base na pedagogia das competências assume papel estratégico para o capital. A ela nos contrapomos defendendo a formação omnilateral, emancipatória na perspectiva socialista.

Portanto, o esporte e o lazer assim como a educação em geral, enquanto políticas culturais, devem contemplar a emancipação humana, tendo como horizonte histórico a sociedade. A perspectiva é, segundo Taffarel et al. (2006) aprofundarmos relações com os movimentos de luta e continuarmos avançando nas contribuições para a formação de professores de Educação Física na perspectiva da emancipação humana.

\title{
Teacher education programs for city and country physical education teachers
}

\begin{abstract}
This text argues that an education program for physical education teachers should be built on five sources of information: 1 . The demands presented by public school, social movements and other entities related to sports and leisure activities in the city and in the country; 2. An assessment of the facilities available for the offering of physical education courses; 3 . A critical evaluation of the literature produced on the theme; 4. The discussion of available projects in the definition of guidelines for teacher education programs for physical education teachers and in the creation of the CREFE/CONFEF System and in the approval of professional regulations; 5. Proposals for the restructuring of the teacher education program syllabus for physical education teachers as proposed by the LEPEL/FACED/UFBA Group.
\end{abstract}

KEYWORDS: teacher education - course syllabus - pedagogical work 
Formación de profesores de educación física para la ciudad y el campo

\section{RESUMEN}

El texto propone la formación de profesores de Educación Física basada en cinco fuentes de datos a saber: 1 . Demandas presentadas por la escuela pública, por los movimientos sociales y entidades relacionadas al área de deporte y ocio de la ciudad y del campo; 2. Evaluación de las condiciones de ofrecimiento de los cursos de educación física; 3. Balance crítico de la producción del conocimiento sobre el tema; 4. Choque de proyectos presentes en la definición de directrices para la formación de profesores de Educación Física en la creación del sistema CREFE/CONFEF y en la aprobación del reglamentación de la profesión; 5. Proposiciones para la reestructuración del curriculum de formación de profesores de la Educación Física presentado por el Grupo LEPEL/FACED/UFBA.

PALABRAS-CLAVE: formación de profesores - curriculun - trabajo pedagógico

\section{NOTA}

1 Dados do Relatório de 2004 do Ministério da Educação sobre o Desenvolvimento da Educação no Brasil.

\section{REFERÊNCIAS}

CARVALHO, M. S. de. A formação de professores e movimentos sociais: a universidade necessária. 2004. 122 p. Dissertação (Mestrado em Educação) - Faculdade de Educação, Universidade Federal da Bahia, Salvador, 2004.

COLETIVO DE AUTORES. Metodologia do Ensino de Educação Física. São Paulo: Cortez, 1992.

CHESNAIS, F. A mundialização do capital. São Paulo: Xamã, 1996.

FREIRE, P. Pedagogia do oprimido. Rio de Janeiro: Paz e Terra, 1977.

FREITAS, L. C. de. Projeto histórico, ciência pedagógica e "didática". Educação e Sociedade, São Paulo, ano 9, n. 27, 122-140, 1987.

. Crítica da organização do trabalho pedagógico e da didática. Campinas: Papirus, 1995. 
GEORGE; S. A falência do sistema liberal. Atenção, São Paulo, ano 1, n. 1, p. 50-53, nov. 1995.

GADOTTI, M.; GUTIERREZ, F. (Org.). Educação Comunitária e economia popular. São Paulo: Cortez, 1993.

GADOTTI, M. Paulo Freire: uma biobibliografia. São Paulo: Cortez, 1996.

IBGE. Disponível em: <http://www.ibge.gov.br/home/estatistica/populacao/pesquisa_esporte2003/esporte2003.pdf. Comunicação Social>. Acesso em: 24 março 2006.

LACKS, S. Formação de professores: a possibilidade da prática como articuladora do conhecimento. 2004. 276 p. Tese (Doutorado em Educação) - Faculdade de Educação, Universidade Federal da Bahia, Salvador, 2004.

MARX, K.; ENGELS, F. A ideologia alemã. 11. ed. São Paulo: Hucitec, 1999.

MARX, K. Contribuições à crítica da economia política. 2. ed. São Paulo: Martins Fontes, 1983.

PICANÇO, I.; TIRIBA, L. V. Trabalho e Educação: arquitetos, abelhas e outros tecelões da economia popular solidária. Aparecida, SP: Idéias \& Letras, 2004. Disponível em: <http://www.ibge.gov.br>. Acesso em: 25 mar. 2006.

SANTOS JR., C. L. Formação de professores e parâmetros teórico metodológicos. 2005. 104 p. Tese (Doutorado em Educação) - Faculdade de Educação, Universidade Federal da Bahia, Salvador, 2005.

TAFFAREL, C. N. Z. A formação do profissional da educação: o processo de trabalho pedagógico e o trato com o conhecimento no curso de Educação Física. 1993. 301 p. Tese (Doutorado em Educação) - Faculdade de Educação, Universidade Estadual de Campinas, Campinas, 1993.

TAFFAREL, C. N. Z.; COLAVOLPE, C. R. Sistema de complexo temáti$c o$ : uma contribuição para o debate de reestruturação curricular do Curso de Educação Física da Universidade Federal da Bahia. Disponível em: $<$ http://www.faced.ufba.br/rascunho_digital/>. Acesso em: 29 mar. 2006. 
TAFFAREL, C. N. Z.; TEIXEIRA, D. R. Cultura corporal e território como complexo temático na formação de professores: uma contribuição ao debate sobre reconceptualização curricular. Disponível em: $<\mathrm{http}: / /$ www.faced.ufba.br/rascunho_digital/>. Acesso em: 29 mar. 2006.

TAFFAREL, C. N. Z. et al. Formação de militantes culturais e alternativas de desenvolvimento da cultura corporal, esporte e lazer em áreas de reforma agrária. Disponível em: $<\mathrm{http}: / /$ www.faced.ufba.br/rascunho_digital/>. Acesso em: 29 mar. 2006.

TAFFAREL, C. N. Z.; DANTAS FILHO, H. Formação de professores de educação física: a história como matriz científica. Disponível em: $<\mathrm{http} / /$ www.faced.ufba.br/rascunho_digital/>. Acesso em: 29 mar. 2006.

Recebido: 31 de março de 2006 Aprovado: 10 de abril de 2006

Endereço para correspondência: Faculdade de Educação da Universidade Federal da Bahia Rua Miguel Calmon, s/n, Vale do Canela Salvador - Bahia CEP 40110-100 A/C Celi Nelza Zülke Taffarel - Tel. 7132637241 E-mail: taffarel@ufba.br 
